\title{
Z-BeEAM (Ibritumomab tiuxetan, Bendamustine, Etoposide, Cytarabine, Melphalan) before autologous stem cell transplantation is safe and efficient for refractory large B-cell lymphoma
}

\author{
Magalie P. Tardy ${ }^{1 *}$, Lauris Gastaud ${ }^{1}$, Mario Ojeda-Uribe ${ }^{2}$, Annick Boscagli ${ }^{1}$, Salvatore Caruso ${ }^{3}$, Richard Skaf ${ }^{4}$, \\ Jean Gutnecht ${ }^{5}$, Antoine Thyss ${ }^{1}$ and Frédéric Peyrade ${ }^{1}$
}

\begin{abstract}
Background: Refractory or relapsed large B-cells lymphoma are usually treated with a high dose chemotherapy regimen followed by an autolougous stem cells transplantation. BEAM (carmustine, etoposide, cytarabine, melphalan) or more recently Z-BEAM (ibritumomab tiuxetan and BEAM) are commonly used regimens, but recently carmustine availability became difficult. The purpose of this study was to evaluate the feasibility and the safety of replacing carmustine by bendamustine in a new Z-BeEAM regimen (ibritumomab tiuxetan, bendamustine, etoposide, cytarabine, melphalan) prior to autologous stem cell transplantation.

Findings: This study was a retrospective analyze of six patients, with a median age of 60 , treated by Z-BeEAM before autologous stem cell transplantation. We did not put in evidence any additional toxicities compared to conventional induction chemotherapy. The main toxicities were mucositis (3 grade III among 6 patients), gastrointestinal (2 grade III vomiting and 2 grade III diarrhea) and neutropenia (6 grade IV). Engraftment was successfully achieved for all patients. At the time of analysis of this study all patients were alive and in complete response based on the PET-CT evaluation.
\end{abstract}

Conclusions: BeEAM plus ibritumomab tiuxetan combined regimen before autologous stem cell transplantation is feasible and safe in aggressive relapsing large B-cell lymphoma.

Keywords: Aggressive Non-Hodgkin lymphoma, Large B cell lymphoma, Autologous stem cell transplantation, Conditionning regimen, Z-BeEAM

\section{Introduction}

Diffuse large B-cell lymphoma (DLBCL) is usually associated with good prognosis. Two-thirds of patients will be cured after classical chemotherapy ( $\mathrm{R}-\mathrm{CHOP}$ or RACVBP). However, for relapsing or refractory aggressive DLBCL, high-dose chemotherapy (HDT) followed by autologous stem cell transplantation (ASCT) is the standard treatment if the patient is able to tolerate this intensive protocol $[1,2]$.

\footnotetext{
*Correspondence: magalie.tardy@gmail.com

'Department of Oncology, Antoine-Lacassagne Center, Nice, France

Full list of author information is available at the end of the article
}

BEAM (carmustine, etoposide, cytarabine, melphalan) is the most commonly used chemotherapy for intensification prior to ASCT [3]. Recently, it has been proven that adding yttrium-90 ibritumomab tiuxetan (Zevalin; Spectrum Pharmaceuticals, Irvine, CA), a radiolabeled anti-CD20 monoclonal antibody, to BEAM is safe and increases both progression-free survival (PFS) and overall survival (OS) in patients with DLBCL [4]. The 2-year OS was $91 \%$ in the Z-BEAM group compared to $62 \%$ in the BEAM group $(\mathrm{p}=0.05)$, with no significant additional toxicity. 
In recent months, there has been a supply problem regarding carmustine, used in the BEAM protocol [5]. Some teams involved in ASCT have tried to replace carmustine with bendamustine, another alkylating agent, which also has the antimetabolite activity of the purine analog structure. A phase I-II study showed the safety and efficacy of bendamustine coupled with etoposide, cytarabine and melphalan (BeEAM) in the conditioning regimen to ASCT for refractory or relapsed DLBCL. $72 \%$ of patients with resistant lymphoma who underwent BeEAM regimen prior to ASCT were still in complete remission 3 years after treatment [6].

This present study demonstrates the feasibility and safety of high dose chemotherapy using the Z-BeEAM regimen with a retrospective analysis of 6 patients treated for relapsed lymphoma.

\section{Material and methods Patient population}

All patients with $\mathrm{CD}_{20} 0^{+}$-aggressive non-Hodgkin lymphoma treated with a Z-BeEAM conditioning regimen prior to ASCT at the Centre Antoine Lacassagne, Nice, and at the Centre Hospitalier, Mulhouse, France, were retrospectively analyzed. Six patients received this

Table 1 Patients and disease characteristics

\begin{tabular}{ll}
\hline Characteristics & Number of patients \\
\hline Median age : years (range) & 60 (51-66) \\
Gender & 5 \\
- Male & 1 \\
- Female & \\
Performans Status (PS) & 6 \\
- 0 & 0 \\
- >0 & \\
Disease stage & 0 \\
- $\leq 2$ & 6 \\
- >3 & \\
Number of previous chemotherapies & 1 \\
- 1 & 3 \\
- 2 & 2 \\
- 3 & \\
Disease status at transplantation & 3.5 (7-12) \\
- Complete response & 3 \\
- Partial response & 3 \\
PET-CT before transplantation & \\
- Negative & \\
- Positive & \\
Median time between diagnosis or & \\
\hline
\end{tabular}

salvage therapy between August 2014 and March 2015. Characteristics of patients are presented in Table 1.

Before treatment, all patients were evaluated with a clinical examination, echocardiography, abdominal echography and biologic and serologic tests. Response to chemotherapy was evaluated before ASCT by positron-emission tomography with computed tomography (PET-CT).

\section{Collection and processing of progenitor cells}

Peripheral blood stem cells were collected either during recovery after an induction chemotherapy cycle, or during a specific mobilization procedure using cyclophosphamide $\left(1.5 \mathrm{~g} / \mathrm{m}^{2}\right)$. Between one and three leukaphereses were performed after stimulation using filgrastim $5 \mu \mathrm{g} / \mathrm{kg} / 12 \mathrm{H}$ to obtain at least 2 million $\mathrm{CD} 34^{+}$cells $/ \mathrm{kg}$. When insufficient circulating $\mathrm{CD}^{+} 4^{+}$cells were obtained with filgrastim, leukapheresis was performed after plerixafor injection.

\section{Conditioning regimen}

The day of peripheral-blood stem cell reinjection, performed as a direct venous infusion, was considered as day 0 . The conditioning regimen started effectively on day -21 with an injection of rituximab $\left(250 \mathrm{mg} / \mathrm{m}^{2}\right)$, followed on day -14 by a second injection of rituximab and an injection of ibritumomab (1200UI). Patients were then hospitalized and, from day -7 to day -1 , received the BeEAM regimen consisting of bendamustine (day -7 at $180 \mathrm{mg} / \mathrm{m}^{2}$ ), etoposide and cytarabine (from day -6 to day -2 at $200 \mathrm{mg} / \mathrm{m}^{2}$ every $\left.12 \mathrm{~h}\right)$, melphalan $\left(140 \mathrm{mg} / \mathrm{m}^{2}\right)$ and amifostine $\left(740 \mathrm{mg} / \mathrm{m}^{2}\right)$ on day -1 .

\section{Supportive care and clinical monitoring}

All patients were hospitalized in single rooms in reverse isolation and received antimicrobial prophylaxis until neutrophil recovery with ciprofloxacine (500 $\mathrm{mg}$ per os every $12 \mathrm{H}$ ), fluconazole (200 mg intravenously every $12 \mathrm{H}$ ) and oral decontamination using diluted vancomycin. Broad-spectrum antibiotics (ceftazidime) were given in case of febrile neutropenia. When invasive fungal infection or fever lasted more than 5 days, an antifungal (voriconazole) was added. Hematopoietic growth factors (filgrastim $5 \mu \mathrm{g} / \mathrm{kg} /$ day) were given from day 5 to the end of aplasia. Platelet transfusion was performed when the platelet count was $<10 \times 10^{9} / \mathrm{L},<20 \times 10^{9} / \mathrm{L}$ in case of fever or bleeding and $<50 \times 10^{9} / \mathrm{L}$ in case of disseminated intravascular coagulation. Packed RBCs were administered to maintain a hemoglobin level $>8 \mathrm{~g} / \mathrm{dl}$. Patients underwent daily physical examination and blood test during hospitalization. Cotrimoxazole and acyclovir were then administered for 6 months after ASCT to prevent pneumocystis jirovecii and viral infections. 


\section{Data collection and objectives}

All adverse events occurring during the treatment period were graded using the Common Terminology Criteria for Adverse Events (CTCAE version 4.0). Each patient underwent a CT-Scan and a PET-CT three months after ASCT to assess response (complete remission or partial response) [7]. The main objective of this study was to analyze the safety of the Z-BeEAM protocol used as high-dose chemotherapy followed by ASCT, considering the incidence and the grade of early adverse effects.

\section{Results}

\section{Patients and treatment characteristics}

There were 5 males and 1 female, with a median age of 60 years (range 51-66). All received at least one rituximab-containing chemotherapy before salvage therapy. One of the six patients had already received a first ASCT in 2008 and relapsed in 2014. Five patients had at least 2 different lines of chemotherapy before HDT and ASCT, and one also had radiotherapy in addition to chemotherapy. Two patients had a mantle lymphoma, three had a diffuse large cell lymphoma, and one had a follicular lymphoma. All were PS 0 at the time of ASCT.

Three patients were in complete response when they underwent ASCT, and 3 in partial response. Median time between diagnosis or relapse and ASCT was 8.5 months $(7-13)$.

The mean number of reinjected $\mathrm{CD} 4^{+}$cells was $2,165.10^{6} / \mathrm{kg}$ (Table 2). Stem cell mobilization was achieved with G-CSF alone in 3 cases. Two other patients needed adjunction of perixafor and one required the use of cyclophosphamide $\left(1.5 \mathrm{~g} / \mathrm{m}^{2}\right)$.

\section{Toxicity}

Early toxicity data are presented in Table 3. All patients presented grade IV neutropenia, reached in a median time of 7 days after the beginning of chemotherapy, except for one patient who presented neutropenia before starting chemotherapy. The median time to obtain an absolute neutrophil count $>0.5 \times 10^{9} / \mathrm{L}$ was 12 days. Engraftment was successfully achieved in all patients. All patients experienced at least grade III thrombopenia and anemia with a median need of 6 platelet transfusions (3-13) and 2 red blood cell transfusions (0-6) (Table 2). One of the other

Table 2 Engraftment characteristics

\begin{tabular}{ll}
\hline Engraftment characteristics & Values (range) \\
\hline Median number of CD34 ${ }^{+}$reinfused & $2,165.10^{6}$ \\
Median time to PNN $>0.5 .10^{6}$ (days) & $12(9-23)$ \\
Median time to reach aplasia (days) & $7(0-9)$ \\
Median days to hospital discharge (days) & $26(20-26)$ \\
Number of CGR transfusions & $2(0-6)$ \\
Number of CPA transfusions & $6(3-13)$ \\
\hline
\end{tabular}

Table 3 Non-hematologic early toxicities

\begin{tabular}{lllll}
\hline Toxicity & $\begin{array}{l}\text { All grades } \\
\text { (number of patients) }\end{array}$ & $\begin{array}{l}\text { Grade } \\
\text { I-II }\end{array}$ & $\begin{array}{l}\text { Grade } \\
\text { III }\end{array}$ & $\begin{array}{l}\text { Grade } \\
\text { IV }\end{array}$ \\
\hline Mucositis & 6 & 3 & 3 & 0 \\
Gastro-intestinal & & & & \\
- Nausea/vomititis & 3 & 1 & 2 & 0 \\
- Diarrhea & 5 & 3 & 2 & 0 \\
Fever & 6 & 5 & 1 & 0 \\
Documented infection & 1 & & & \\
Cardiac arrythmia & 0 & & & \\
$\begin{array}{l}\text { Pulmonary toxicities } \\
\text { (pneumonitis) }\end{array}$ & 0 & & & \\
\hline
\end{tabular}

major side-effects observed was mucositis; 3 patients presented grade III mucositis requiring morphinic treatment, one patient presented grade II mucositis and 2 had grade I. Gastrointestinal toxicities were frequently found with 2 patients presenting grade III diarrhea and 2 grade III vomiting. All patients presented fever during their neutropenia period requiring empiric antibiotherapy and antifungal therapy was added in one case. These febrile neutropenias were all easily managed with these treatments and none have evolved to septic shock. No patients died during the treatment.

\section{Response to treatment}

The mean follow-up period was 5 months (0-10). At the end-point ( $1^{\text {st }}$ March 2015), all patients were alive and in complete response based on clinical examination, biological examination and on the PET-CT results.

\section{Discussion}

High-dose chemotherapy followed by ASCT is the standard treatment for refractory or relapsed aggressive DLBCL [2], usually reserved for young ( $<65$ years) and fit patients. Various conditioning regimens have been used prior to ASCT with no evidence that one is superior to the others. However, the BEAM regimen is the most widely used due to its limited morbidity and toxicities, and with comparable efficacy $[8,9]$. It has also been proven that the BEAM regimen is effective and safe for selectionned elderly patients [10] with a good performans status.

However, the CORAL study [1] demonstrated that patients with relapsed DLBCL, previously treated with rituximab, do very poorly after ASCT. Since rituximab is now widely used, it has become necessary to develop novel approaches to enhance these results. One of them has been the addition of radioimmunotherapy as part of the conditioning regimen prior to autologous stem cell transplantation [11]. Fruchart et al. [4] studied the association of ibritumomab and the BEAM regimen prior to ASCT for patients receiving a first rituximab-containing 
chemotherapy. They observed an overall response rate of $86 \%$, and a 2-year event-free survival of $79 \%$. Furthermore, it is safe to add ibritumomab to the BEAM regimen with no increase in toxicity except for mucositis with a majority of grade III [12]. The results of our small retrospective study show that no additional toxicities are observed when adding ibritumomab to the BeEAM protocol. The duration of grade IV neutropenia is similar to that described in the majority of studies using a classical BEAM regimen [13]. There was no difference in engraftment compared with other studies and transfusion needs were similar to those previously reported with BEAM, BeEAM or Z-BEAM regimens. The principal toxicities noted were gastrointestinal toxicity and mucositis. This was expected as similar studies using radioimmunotherapy revealed same type and level of toxicity.

The main limitation of our study is the small number of patients and the short follow-up period which has not allowed us to explore long-term response and delayed toxicity. It would be interesting to search for late cardiac and hematologic toxicity, especially myelodysplasic syndrome. Another important question would be the strategy to adopt in patients relapsing after treatment containing rituximab, ibritumomab and BeEAM prior to

BeEAM (bendamustine, etoposide, cytarabine, melphalan) plus yttrium-90 ibritumomab tiuxetan combined regimen before autologous stem cell transplantation is feasible in aggressive relapsing large B-cell lymphoma. Further prospective clinical trials are needed to confirm our preliminary results.

\section{Abbreviations}

ASCT: autologous stem cell transplantation; BEAM: Carmustine, Etoposide, Cytarabine, Melphalan; BeEAM: Bendamustine, Etoposide, Cytarabine, Melphalan; DLBCL: diffuse large B cell lymphoma; HDT: high dose (chemo)therapy; OS: overall survival; PFS: progression-free survival.

\section{Competing interests}

The authors declare that they have no competing interests. ASCT.

\section{References}

1. Gisselbrecht C, Glass B, Mounier N, Singh Gill D, Linch DC, Trneny M, et al. Salvage regimens with autologous transplantation for relapsed large B-cell lymphoma in the rituximab era. J Clin Oncol . 2010;28:4184-90.

2. Philip T, Guglielmi C, Hagenbeek A, Somers R, Van der Lelie H, Bron D, et al. Autologous bone marrow transplantation as compared with salvage chemotherapy in relapses of chemotherapy-sensitive non-Hodgkin's lymphoma. N Engl J Med. 1995;333:1540-5.

3. Mounier N, Gisselbrecht C. Conditioning regimens before transplantation in patients with aggressive non-Hodgkin's lymphoma. Ann Oncol. 1998;9 Suppl 1:S15-21.

4. Fruchart $C$, Tilly $H$, Morschhauser $F$, Ghesquières $H$, Bouteloup M, Fermé $C$, et al. Upfront consolidation combining yttrium-90 ibritumomab tiuxetan and high-dose therapy with stem cell transplantation in poor-risk patients with diffuse large B cell lymphoma. Biol Blood Marrow Transplant. 2014;20:1905-11.

5. Shimoni A, Avivi I, Rowe JM, Yeshurun M, Levi I, Or R, et al. A randomized study comparing yttrium-90 ibritumomab tiuxetan (Zevalin) and high-dose BEAM chemotherapy versus BEAM alone as the conditioning regimen before autologous stem cell transplantation in patients with aggressive Iymphoma. Cancer. 2012;118:4706-14.

6. Visani G, Malerba L, Stefani PM, Capria S, Galieni P, Gaudio F, et al. BeEAM (bendamustine, etoposide, cytarabine, melphalan) before autologous stem cell transplantation is safe and effective for resistant/relapsed lymphoma patients. Blood. 2011;118:3419-25.

7. Cheson BD, Fisher RI, Barrington SF, Cavalli F, Schwartz LH, Zucca E, et al. Recommendations for Initial Evaluation, Staging, and Response Assessment of Hodgkin and Non-Hodgkin Lymphoma: the Lugano Classification. J Clin Oncol. 2014;32:3059-67.

8. Fernandez HF, Escalón MP, Pereira D, Lazarus HM. Autotransplant conditioning regimens for aggressive lymphoma: are we on the right road? Bone Marrow Transplant. 2007:40:505-13.

9. Mills W, Chopra R, McMillan A, Pearce R, Linch DC, Goldstone AH. BEAM chemotherapy and autologous bone marrow transplantation for patients with relapsed or refractory non-Hodgkin's lymphoma. J Clin Oncol. 1995;13:588-95.

10. Martin N, Borchiellini D, Coso D, Gastaud L, Boscagli A, Saudes L, et al. High-dose chemotherapy with carmustine, etoposide, cytarabine and melphalan followed by autologous stem cell transplant is an effective treatment for elderly patients with poor-prognosis lymphoma. Leuk. Lymphoma 1-9 (2015). Epub ahead of print. doi:10.3109/ 10428194.2014.1001987

11. Auger-Quittet S, Duny Y, Daures J-P, Quittet P. Outcomes after (90) Yttrium-ibritumomab tiuxetan-BEAM in diffuse large B-cell lymphoma: a meta-analysis. Cancer Med. 2014;3:927-38.

12. Zinzani PL, Gandolfi L, Stefoni V, Fanti S, Fina M, Pellegrini C, et al. Yttrium-90 ibritumomab tiuxetan as a single agent in patients with pretreated B-cell lymphoma: evaluation of the long-term outcome. Clin Lymphoma Myeloma Leuk. 2010;10:258-61.

13. Visani G, Stefani PM, Capria S, Malerba L, Galieni P, Gaudio F, et al. Bendamustine, etoposide, cytarabine, melphalan, and autologous stem cell rescue produce a $72 \% 3$-year PFS in resistant lymphoma. Blood. 2014;124:3029-31.

\section{Submit your next manuscript to BioMed Central and take full advantage of:}

\begin{abstract}
SC RS J I MPT and FP wrote the paper. All authors read and approved the final manuscript.

\section{Author details}

'Department of Oncology, Antoine-Lacassagne Center, Nice, France. 2Department of Hematology, Mulhouse Hospital, Mulhouse, France. ${ }^{3} \mathrm{La}$ Dracenie Hospital Center, Draguignan, France. ${ }^{4}$ Department of Oncology, Saint-Georges Clinic, Nice, France. ${ }^{5}$ Department of Oncology, Frejus-Saint Raphael Hospital, Frejus, France.

Authors' contributions

MPT was the principal investigator; LG and AB performed the transplant and
\end{abstract} 1.
- Convenient online submission

- Thorough peer review

- No space constraints or color figure charges

- Immediate publication on acceptance

- Inclusion in PubMed, CAS, Scopus and Google Scholar

- Research which is freely available for redistribution 